Bika, Z., \& Joy, S. 2018. Family Business as a longstanding hybrid organisation: Logic revision as a strategy for maintenance. DOI: In Guclu Atinc (Ed.) Proceedings of the Seventy-eight Annual Meeting of the Academy of Management. Online ISSN: $2151-6561$.

\title{
FAMILY BUSINESS AS A LONGSTANDING HYBRID ORGANISATION: LOGIC REVISION AS A STRATEGY FOR MAINTENANCE
}

\author{
ZOGRAFIA BIKA \\ University of East Anglia (UEA) \\ Norwich Business School, Norwich NR4 7TJ, United Kingdom \\ SIMY JOY \\ University of East Anglia (UEA), Norwich
}

\begin{abstract}
Hybrid organisations, organisational forms that combine multiple institutional logics, have recently attracted substantial scholarly attention. Ongoing maintenance of hybridity has been identified as a key challenge for hybrid organisations. This paper puts forward family businesses that integrate family and business logics as the world's oldest and the most pervasive form of hybrid organisation, and explores their organisational maintenance strategies for sustaining such hybridity. Based on an oral history study of longstanding family businesses in Scotland, we propose 'logic revision', i.e. a socially constructed and evolving reinterpretation of logics, as another strategy for organisational maintenance in the hybrid organisational context. As opposed to the known strategies of decoupling, compromising, structural separation and selective coupling that rely on the deterministic properties of institutional logics, this strategy draws on their socially constructed nature.
\end{abstract}

\section{INTRODUCTION}

Recent years have witnessed a tremendous rise in the research on hybrid organisational forms, i.e. organisational forms that combine multiple institutional logics. This research suggests that a key challenge for hybrids is maintaining their hybridity, i.e. ensuring the ongoing and simultaneous presence of the multiple logics they seek to combine without one of them displacing the other (Ebrahim, Battilana \& Mair, 2014).

We observe that family businesses, which combine the institutional logics of family and business, probably are the oldest and the most pervasive form of hybrid organisation the world over, and could be a source of lessons in maintaining logic multiplicity and thereby organisational hybridity. In this paper, based on an oral history study of longstanding and well-performing family businesses in Scotland, we propose 'logic revision', i.e. a socially constructed and evolving reinterpretation of logics, as another intra-organisational strategy for maintaining both family and business logics as central pillars of the organisational form. We find that while the prevalent intraorganisational strategies are based on a deterministic notion of logics that allows only for singular interpretations, i.e. each logic seen as offering a unique organising template with a specific means and ends attribution, logic revision is based on a more dynamic notion of logics where means and ends are subject to reinterpretation and reattribution.

\section{THEORETICAL BACKGROUND}

Logic multiplicity is the defining feature of hybrid organisational forms (Gonin et al., 
Bika, Z., \& Joy, S. 2018. Family Business as a longstanding hybrid organisation: Logic revision as a strategy for maintenance. DOI: In Guclu Atinc (Ed.) Proceedings of the Seventy-eight Annual Meeting of the Academy of Management. Online ISSN: $2151-6561$.

2013). The incompatibility of logics that constitute the hybrid organisations is seen as a key challenge in ensuring continuing centrality of those logics in the day-to-day organisational functioning (Battilana \& Dorado, 2010; Mair, Mayer \& Lutz, 2015; Pachos \& Santos, 2013). It is feared that the incompatibility of the ends and means prescribed by the organising templates associated with the constituent logics may not always be reconciled, leading to one of the logics growing more influential in guiding the core organisational activities, and the other increasingly being regarded irrelevant to the core and relegated to the peripheries (Besharov \& Smith, 2014). Field level studies that trace historically the dynamics among competing logics have often confirmed such emergence of a single logic as the dominant one (Berman, 2012). We argue that the maintenance of the hybrid organisational form depends on the maintenance of logic multiplicity, and entails accommodating and reconciling logic incompatibilities, as well as ensuring ongoing relevance of the logics to the organisational core.

Organisational maintenance is a vastly under-theorised and under-researched area, in comparison to the creation or change of organisations and institutional orders (Lawrence \& Suddaby, 2006; Scott, 2001). The notion of institutions as self-reproducing (Jepperson, 1991) renders an implicit definition of maintenance as 'simple stability or absence of change' (Lawrence \& Suddaby, 2006: 234). Drawing on Oliver's (1992) work on deinstitutionalisation, Lawrence and Suddaby (2006: 217), point out that the strategic and operational environments for organisations are constantly evolving, and organisations cannot persist in contexts of such continual 'upheaval and change' unless actors engage in conscious processes for ensuring their organisations' continuity (Lawrence \& Suddaby, 2006: 234). Maintenance from this perspective may be redefined as purposive acts of 'preservation and reinforcement' (Micelotta \& Washington, 2013: 1139) by the incumbent actors of the institutional logics and arrangements underpinning their organisations, in order 'to neutralise potential threats' (Micelotta \& Washinton, 2013: 1140), pre-empt obsolescence (Oliver, 1992), and to sustain their ongoing relevance. The emergent empirical literature on organisational maintenance stresses (on the micro-level) intra-organisational work undertaken by the actors as pivotal for maintenance (Currie et al., 2012; Dacin, Munir \& Tracey, 2010; Micelotta \& Washington, 2013). Lawrence and Suddaby (2006) observe that maintenance strategies broadly fall into two categories: those for preserving the symbolic and normative foundations, and those for ensuring adherence to associated practices.

We note that the literature on strategies for organisational maintenance specific to hybrid organisations has not yet come together as a coherent stream. The extant research, based primarily on social enterprises, a nascent category of hybrids (Battilana \& Dorado, 2010; Ebrahim, Battilana \& Mair, 2014; Mair, Mayer \& Lutz, 2015; Pache \& Santos, 2013), reports various strategies for maintaining intra-organisational hybridity, including decoupling (i.e. symbolic endorsement of one logic, while actually following the other logic in practice, see Meyer \& Rowan, 1977), compromising (i.e. abiding to the minimum expected standards, see Oliver, 1991), structural separation (i.e. containment of logics within different parts of the organisation, by allowing various groups of organisational actors, units, departments and geographic locations to function based on different logics, see Gonin et al., 2013; Reay \& Hining, 2009) and more recently, selective coupling (i.e. purposeful combining of intact elements of the symbolic systems and material practices of competing logics, see Pachos \& Santos, 2013). We observe that these strategies are underpinned by a deterministic notion of institutional logics, where each logic is treated as a static template with pre-determined configurations of ends and means. They therefore may have only a limited ability to accommodate a dynamic and reflexive maintenance of institutional templates, which the organisational maintenance scholars have found essential for long-term maintenance. 
Bika, Z., \& Joy, S. 2018. Family Business as a longstanding hybrid organisation: Logic revision as a strategy for maintenance. DOI: In Guclu Atinc (Ed.) Proceedings of the Seventy-eight Annual Meeting of the Academy of Management. Online ISSN: $2151-6561$.

\section{RESEARCH METHODOLOGY}

This paper is based on 49 oral history interviews of interrelated owner-managers of longstanding and well-performing Scottish family businesses. We found this data source to be ideal for our enquiry as we regard the business family as being the central actor engaged in the preservation of logics, with owner-managers as the voice of the business family. Business families are distinguished not only "by the fact that they have tried to perpetuate a particular set of controlling ownership interests in operating family businesses" (Marcus, 1991: 77) but also attitudes, knowledge and capabilities. In this study, we approach the owner-managers as representatives of business families to gain insights of the business family perspectives on logic and organisational maintenance. Our chosen area of focus is HRM - in other words an area in the internal functioning of family businesses, where the duality of family and business logics has been widely recognised, and identified as problematic. Following Reay \& Jones' (2016) recommendations for qualitatively capturing institutional logics, we adopted a "pattern-inducing technique" that involves a bottom-up, inductive approach in our analysis. Additionally, we gathered archival and other financial data (e.g. annual reports, online materials, press releases, company history books). Going back and forth between our multi-source data and the literature allowed us to rule out the possibilities of known strategies for organisational maintenance being in play in our context and uncover a new strategy and its associated processes.

\section{FINDINGS}

Our analysis of how owner-managers 'inhabit' competing logics inside the family organisation and in the area of HRM, started with an analysis of the material practices, as they were the more easily identifiable aspects in the instantiations of logics. However, as we categorised the commonly described HRM practices, we noticed that owner-managers made explicit statements about 'what they did' as well as 'what they did not do'. Although at first it looked similar to selectively combining components from both logics as portrayed in the selective coupling strategy (Pachos \& Santos, 2013), a deeper exploration of 'why they did/didn't follow' certain practices guided us to the belief system underlying those practices. We saw that their underlying system of symbolic structures and beliefs drew on both family and business logics, but the way they integrated these logics was far messier and complex than a mere (re)combining of intact elements (Pache \& Santos, 2013). The elements of the logics were not just taken as a given, but were broken, reconstructed, reinterpreted and reattributed in this messy process, which we refer to as 'logic revision'. The choice, purpose and enactment of material practices reflected various elements of this revised belief system including the construction of actor interrelationships, goals and values.

\section{Revision of HRM Belief Systems}

In the dominant literature on the human resources in family businesses, 'family' has been the key symbolic system that was used to differentiate between the actors (Jaskiewicz et al., 2013) In this literature, 'family' is understood in the literal sense, i.e. actors who are relations of each other, and the intra-organisational actors are categorised based on family membership, i.e. family employee and non-family employee. In our analysis, we found that the literal construction of family has been revised and replaced with a symbolic construction of family, which presented 
Bika, Z., \& Joy, S. 2018. Family Business as a longstanding hybrid organisation: Logic revision as a strategy for maintenance. DOI: In Guclu Atinc (Ed.) Proceedings of the Seventy-eight Annual Meeting of the Academy of Management. Online ISSN: $2151-6561$.

employees collectively as a family. For example:

'Do I think the 300 people out there are my family? To a degree, yes, I look after them. My employees know that if you have a problem, if you have an alcohol or drugs problem, if you want to give up smoking. If you don't come to me go to one of the other managers and you tell them and they will speak to others who will get things sorted' (Albert_M*Manufacturing, $3^{\text {rd }}$ Generation, 270 employees).

'My hopes match those of the company's current vision which is to sustain a legacy for generations to come. It gives me great pleasure to see not only second and third generation $\mathrm{S}$ [owner family name] family members working within the business, but also many and $3^{\text {rd }}$ generation members of staff as well' (Simon_Sk*Construction, $2^{\text {nd }}$ Generation, 190 employees Company Statement).

'I think there is that sort of expectation from employees and from the managers, that you know we'll look after you if you look after us' (Adam_L*Agriculture, $3^{\text {rd }}$ Generation, 40 employees).

'I have a responsibility to my employees. They are entrusting me with their careers. I've got to be sure that we're not misleading them, they know fully what opportunities lie for them, and then make sure that we give those opportunities to them and we don't cheat them' (Bill_S*Manufacturing, $2^{\text {nd }}$ Generation, 67 employees)

It was noteworthy that this symbolic reconstruction of family included not only the present employees, but also extended spatially to employees' blood and marital relations, and temporally to past employees and future generations. We see this construction of the symbolic family as a departure from, and revision of the notion of family as per family logics, as in this construction the de facto separation between family and non-family employees was downplayed and membership in the symbolic family became consensual. We regard this as an instance of revision because there was a clear resistance against adopting the competing template of actor relationships, namely the contractual and self-interest based actor relations professed by the business logic. The revision in fact was used for reasserting the centrality of 'family', but with a different composition of membership. The conceptualisation of intra-organisational actor interrelationships focused on custodian values and stakeholder commitments as a defining goal of the revised logic.

\section{New HRM Practices As Instantiations Of Revised Belief Systems}

Owner-managers emphasised the difference between 'what is done' and 'what is not done' in terms of practices, and it would seem that 'what is done' largely reflects practices showing family-care philosophy. However, taken together with 'what is not done', they show how it flows from and reinforces the reconstructed notion of employees as symbolic family. Portraying employees as part of symbolic family normalises a family-care approach to HRM. Reflecting the revised HRM belief systems, recruitment and selection focused on providing opportunities for the young, and encouraged the practices of providing summer and regular jobs to young applicants, very commonly acquaintances and employees' offspring, apprenticeship programs and even dedicated academies. Career development and progression practices consisted of providing growth 
Bika, Z., \& Joy, S. 2018. Family Business as a longstanding hybrid organisation: Logic revision as a strategy for maintenance. DOI: In Guclu Atinc (Ed.) Proceedings of the Seventy-eight Annual Meeting of the Academy of Management. Online ISSN: $2151-6561$.

opportunities to existing employees such as trusting them with greater responsibilities, funding their higher education and certifications, and being accommodative of individual career aspirations. The practices related to pay and benefits were guided by the norm of 'providing for the needs' of the employees and their families. They comprised making a fair pay for work which will also satisfy the needs of their employees' family (rather than higher pay), and subjectively disbursing benefits based on individual and family needs (rather than equitable distribution of benefits). Employee retention practices also rose from the norms of providing for the wellbeing of employees, and included HRM practices that did not involve money, such as addressing specific issues a particular employee might be facing, reassigning work in case of personal performance issues and positioning family-like work environment as superior to other work environments. Redundancy related practices were also formed around stakeholder commitments that included employees and their families. The practices around redundancy revolved around avoiding downsizing as an option as long as possible, and when it is no longer avoidable, helping the employees find alternate jobs. Retirement related practices were tied to the norm of 'looking after the old' and included providing for them over and above the statutory requirement. For example:

'Having a long-term view, trusting people and each other, being open, not embracing problems, not walking away from things, just knowing that we'll do this job and we'll do it right and if there's a problem we'll talk about it and sort it out, that we don't all stand in a circle and point to each other and say it's his fault, you know, there's no in-fighting or back-stabbing, we just work with it and get it done; it's a two-way relationship, (our staff) get something back out of it and enjoy being here, not just that they're getting paid to do a job ... my father brings in new people as well, but always people who are in the same, have the same attitude; that's the way the business is run, and sometimes people will call that naive or too trusting but our performance over 40 years speaks for itself; I would hate to see that lost by trying to change the model within the business to accommodate lots of different family members into it' (Barry_W*Construction, 2nd Generation, 73 employees)

'... So people come here and the policy generally is to try and draft in younger people and let them come through the lab or through the plant in a modest way, learn the business and grow with the business, and whenever we have done that it has been a good outcome while it lasts. Very few people have been parachuted in to senior positions; when we have tried that it does not work' (Brian $\mathrm{T}^{*}$ Construction, 1st Generation, 55 employees).

'What I've done and I'm not embarrassed to say this is I had to ask everybody to take a $12 \%$ pay cut, my brother and I took a $100 \%$, I have had no money in the last three months and I'm happy if I have no money for the rest of my life, as long as I make sure every one of the people are paid ... My brother was the managing director, (but) I had to sack my brother and put this young boy in place because he's faster, better, sharper and came through the academy (apprentices)' (Simon_Sk*Construction, 2nd Generation, 190 employees).

'A lot of the tradesmen that we have, in their later years, once they can't produce to the same quantity as they used to, you know, people slow up as they get older, we'll shift them into a maintenance department so that their skills are not; everybody makes mistakes or there's always snagging on jobs to be done' (Donald $\mathrm{O}^{*}$ Construction, 3rd Generation, 623 employees). 
Bika, Z., \& Joy, S. 2018. Family Business as a longstanding hybrid organisation: Logic revision as a strategy for maintenance. DOI: In Guclu Atinc (Ed.) Proceedings of the Seventy-eight Annual Meeting of the Academy of Management. Online ISSN: $2151-6561$.

'We shut the factory in 1999 . We made about 18 people redundant on a Friday. On the Monday all but three had jobs. Some here, some chose to go to other businesses, but we had, I had organised that when we spoke to them just after lunch that anyone that wanted their details to go to a number of businesses would have happened that afternoon and it did. These businesses knew what we were doing and I called them because I knew they needed the skills' (Albert_M*Manufacturing, 3rd Generation, 270 employees).

'We have given them who have been with us for 30 years a profit-based allowance (£8$15 \mathrm{~K})$; We do it because we can afford to do it. It is not a legal agreement that we do it' (Igor_C*Services, 2nd, Generation, 16 employees)

By contrast, reserving key roles for family members, compromising on family members' performance and providing superior salaries and benefits to family members are now part of 'what is not done'. The other practices that were resisted were rooted in the business logic construction of actor relations, which assumes that actor relations are governed by self-interests and formal contractual obligations. These practices included mid-career hiring and parachuting people into senior positions (which compromises the growth interests of the young and existing employees), firing employees citing short-term performance issues, and introducing pay cuts and redundancies to tide over difficult economic conditions. This shows that protecting the coherence of a symbolic construction requires not only its enactment in practices, but also resisting practices originating in alternate constructions.

\section{DISCUSSION AND CONCLUSIONS}

Based on an oral history study of Scottish family businesses, we propose the concept of 'logic revision', as a strategy for accommodating conflicting logics in hybrid organisational forms, and organisational maintenance. Logic revision is centred on the notion of institutional logics i.e. 'socially constructed, historical patterns of cultural symbols and material practices, assumptions, values and beliefs by which individuals produce and reproduce their material subsistence, organise time and space, and provide meaning to their daily activity' (Thornton et al., 2012: 51). Logics here are 'contextual and translated by members for their time and place' (Reay \& Jones, 2016: 441), whilst our understanding of logic revision hinges on the actors' agency in engaging with this translation process. We argue that this is an important, but often insufficiently acknowledged aspect of organisational maintenance - especially in relation to hybridity. Actors from this perspective are capable of going beyond picking and choosing components from the organisational templates provided by different logics (Pachos \& Santos, 2013; Durand et al., 2013) and can be seen to break down, reinterpret and reconstruct the given logics for their purpose and context (McPherson \& Sauder, 2013). We show that such logic revision has enabled owner-managers to advance and sustain a notion of 'family as a means for sustaining the business' in place of both the older notion of 'business as a means for sustaining the family' (Aldrich \& Cliff, 2003) and the prevalent academic notion of 'family as antithetical to business' (Chandler, 1990), thus challenging the implicit 'means-ends designations' currently provided by logics (Pache \& Santos, 2010: 457). Reattribution of means and ends becomes the foundation for an alternate and relatively stable organising template, where both logics remain relevant and central, but not routinely contested.

REFERENCES AVAILABLE FROM THE AUTHOR(S) 